\title{
Erratum to: EEG theta/beta ratio as a potential biomarker for attentional control and resilience against deleterious effects of stress on attention
}

Peter Putman • Bart Verkuil • Elsa Arias-Garcia • Ioanna Pantazi • Charlotte van Schie

Published online: 4 March 2014

(C) Psychonomic Society, Inc. 2014

Erratum to: Cogn Affect Behav Neurosci

DOI 10.3758/s13415-013-0238-7

In the Discussion section, the authors reflect on the (non-)specificity of the findings for frontal recording positions. Due to mistakes made during text editing, the concluding sentence reads as follows: "All in all, the data from this study now allow for firm conclusions concerning the question of whether the (pre)frontal cortex is indeed critically involved (...)". However, this sentence should instead read, "All in all, the data from this study allow no firm conclusions concerning the question of whether the (pre)frontal cortex is indeed critically involved (...)".

The online version of the original article can be found at http://dx.doi.org/ 10.3758/s13415-013-0238-7.

P. Putman $(\bowtie) \cdot$ B. Verkuil • E. Arias-Garcia $\cdot$ I. Pantazi

C. van Schie

Institute of Psychology, Leiden University, Wassenaarseweg 52,

PO Box 9555, 2300 RB Leiden, The Netherlands

e-mail: PPutman@FSW.leidenuniv.nl

P. Putman · C. van Schie

Leiden Institute for Brain and Cognition, Leiden, The Netherlands 